\section{The atoll sign}

A man presented as an urgent referral to the interstitial lung disease outpatient clinic with a 5 week history of fever, night sweats, shortness of breath and malaise. His admission chest $\mathrm{x}$-ray showed patchy consolidation within both lungs, and a subsequent CT demonstrated multiple parenchymal ring opacities (figure 1 and figure 2A). On the basis of the unusual CT appearances he subsequently proceeded to an open lung biopsy which demonstrated polypoid buds of intra-alveolar granulation tissue or Masson bodies, consistent with a histopathological diagnosis of organising pneumonia (figure 3). He was treated with intravenous methylprednisolone and hydroxychloroquine to which he initially responded. Over the next 5 years he had several relapses clinically and radiologically which required pulse doses of methylprednisolone. Once stable, his medication was tapered and eventually stopped. Repeat CT imaging at this time revealed no residual parenchymal abnormalities. No definite cause for his illness was found and, following a multidisciplinary evaluation of his case, a final diagnosis of cryptogenic organising pneumonia was made.

Crescentic or ring-shaped opacities surrounding an area of ground-glass opacification occasionally seen in the setting of organising pneumonia were first described by Voloudaki ${ }^{1}$ and later coined the 'Atoll sign' by Zompatori. ${ }^{2}$ Kim et al. documented it in $19 \%$ of cases of cryptogenic organising pneumonia. ${ }^{3}$ The word Atoll is derived from the Maldivian word 'atholhu' meaning an island consisting of a circular coral reef surrounding a lagoon (figure $2 \mathrm{~B}$ ). Although originally thought to be specific for organising pneumonia, this CT appearance has been described in a variety of other diseases including sarcoidosis, ${ }^{4}$ Wegener granulomatosis, ${ }^{5}$ lymphomatoid granulomatosis, ${ }^{6}$ pulmonary paracoccidiomycosis ${ }^{7}$ and non-specific interstitial pneumonia, ${ }^{8}$ and under different names including the 'reversedhalo' sign and the 'fairy-ring' sign. Histopathologically the ground-glass opacification centrally represents septal inflammation, and cellular debris within the airspaces and the peripheral crescentic or ring-shaped opacity represents organising pneumonia in the alveolar ducts. ${ }^{1}$ From a learning perspective, although this striking CT appearance is well documented in organising pneumonia, it should alert the radiologist and physician to other possible diagnoses, of which Wegener granulomatosis is particularly important.

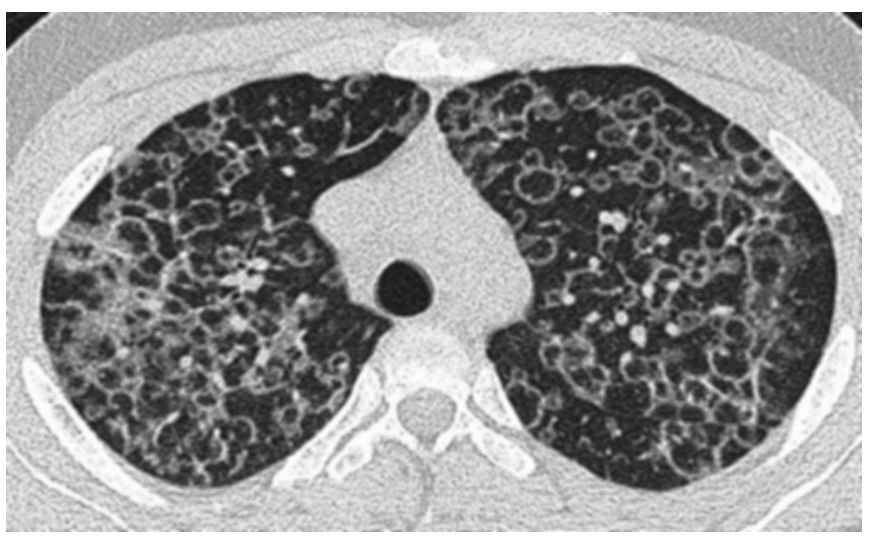

Figure 1 Chest CT at presentation showed innumerable ring opacities, some of which surround a centre of ground-glass opacification, throughout the lung.
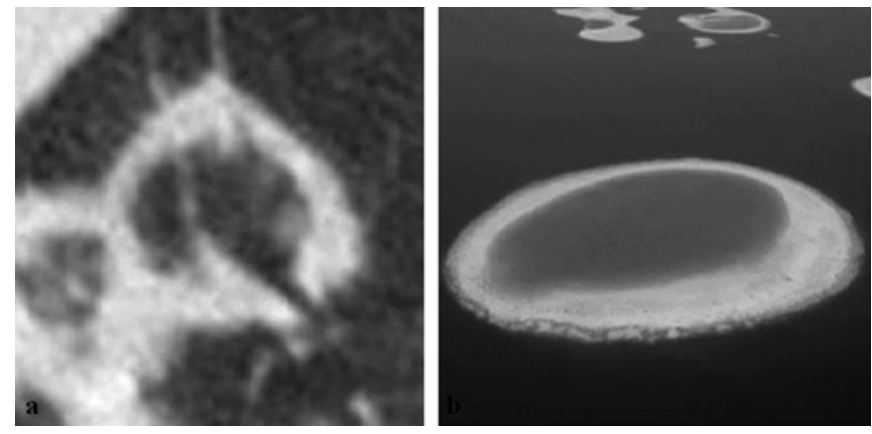

Figure 2 (A) Magnified view of conjoined ring opacities. (B) Aerial view of a Maldivian 'atoll' from which this CT sign derives its name.

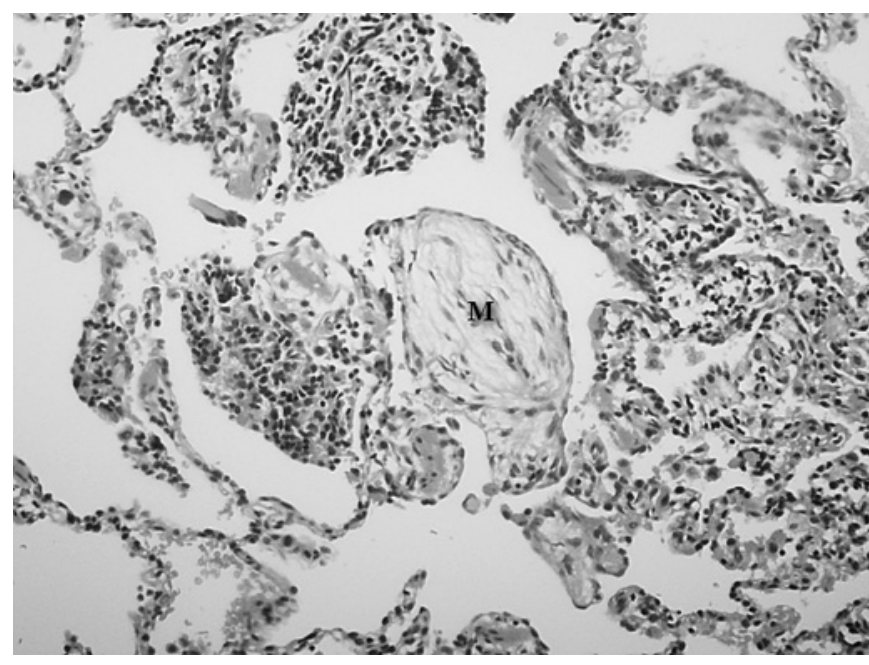

Figure 3 Surgical lung biopsy material demonstrated intra-alveolar polypoid buds of granulation tissue also known as Masson bodies (M).

\section{Learning points}

- The Atoll sign is a well recognised CT pattern associated with organising pneumonia.

- This sign has also been reported in a number of other important conditions which should be considered in the differential diagnosis when interpreting it. In particular, consideration should be given to Wegener granulomatosis.

\section{Simon L F Walsh, Benjamin J Roberton}

Department of Radiology, Royal Brompton Hospital, UK

Correspondence to Simon L F Walsh, Department of Radiology, Royal Brompton Hospital, Sydney Street, London SW3 6NP, UK; slfwalsh@gmail.com

\section{Competing interests None.}

Provenance and peer review Not commissioned; externally peer reviewed.

Accepted 9 June 2010

Published Online First 6 September 2010

Thorax 2010:65:1029-1030. doi:10.1136/thx.2010.139360

\section{REFERENCES}

1. Voloudaki AE, Bouros DE, Froudarakis ME, et al. Crescentic and ring-shaped opacities. CT features in two cases of bronchiolitis obliterans organizing pneumonia (B00P). Acta Radiol 1996;37:889-92. 
2. Zompatori M, Poletti V, Battista G, et al. Bronchiolitis obliterans with organizing pneumonia (BOOP), presenting as a ring-shaped opacity at HRCT (the atoll sign). A case report. Radiol Med 1999;97:308-10.

3. Kim SJ, Lee KS, Ryu YH, et al. Reversed halo sign on high-resolution CT of cryptogenic organizing pneumonia: diagnostic implications. AJR Am J Roentgenol 2003:180:1251-4.

4. Marlow TJ, Krapiva PI, Schabel SI, et al. The "fairy ring": a new radiographic finding in sarcoidosis. Chest 1999;115:275-6.
5. Agarwal R, Aggarwal AN, Gupta D. Another cause of reverse halo sign: Wegener's granulomatosis. Br J Radiol 2007;80:849-50.

6. Benamore RE, Weisbrod GL, Hwang DM, et al. Reversed halo sign in lymphomatoid granulomatosis. Br J Radiol 2007;80:e162-6.

7. Gasparetto EL, Escuissato DL, Davaus T, et al. Reversed halo sign in pulmonary paracoccidioidomycosis. AJR Am J Roentgenol 2005:184:1932-4.

8. Ueda S, Inoue R, Tanaka $\mathrm{K}$, et al. A case of nonspecific interstitial pneumonia with reversed halo sign on chest HRCT. Nihon Kokyuki Gakkai Zasshi 2007:45:248-52.

\section{Notice}

\section{Scadding-Morriston Davies joint fellowship in respiratory medicine 2011}

This fellowship is available to support visits to medical centres in the UK or abroad for the purpose of undertaking studies related to respiratory medicine. Applications are invited from medical graduates practising in the United Kingdom, including consultants and irrespective of the number of years in that grade. There is no application form but a curriculum vitae should be submitted together with a detailed account of the duration and nature of the work and the centres to be visited, confirming that these have agreed to provide the facilities required. Please state the sum of money needed for travel and subsistence. A sum of up to $£ 20000$ can be awarded to the successful candidate, or the sum may be divided to support two or more applications. Applications should be sent to the secretary by 31 January 2011.

\section{Ian Campbell}

Department of Respiratory Medicine, Academic Centre, Llandough Hospital, Cadriff, UK

Correspondence to lan Campbell, Department of Respiratory Medicine, Academic Centre, Llandough Hospital, PENARTH, Vale of Glamorgan CF64 2XX, UK; lan.campbell@wales.nhs.uk

Provenance and peer review Not commissioned; not externally peer reviewed.

Thorax 2010;65:1030. doi:10.1136/thx.2010.152249 